\title{
Maximum Forced Inspiratory Flow
}

National Cancer Institute

\section{Source}

National Cancer Institute. Maximum Forced Inspiratory Flow. NCI Thesaurus. Code C112333.

Forced inspiratory flow for a portion of the FVC curve at the point where the maximum portion of FVC is already inhaled. (CDISC) 